\title{
DIFERENÇA E DESIGUALDADE NA PRIMEIRA REPÚBLICA
}

\author{
Richard Miskolci
}

Em 1885, o criminologista italiano Cesare Lombroso foi citado pela primeira vez em um tribunal brasileiro. Tratava-se do julgamento de um caso de homicídio em que um carvoeiro da rua da Candelária matou seu patrão. $\mathrm{O}$ advogado Ciro Azevedo defendeu o acusado apelando para os estigmas físicos e psíquicos do réu, os quais provariam sua inculpabilidade. O rapaz terminou condenado a 30 anos de prisão e, apesar desse malogro inicial, a Criminologia alcançaria sucesso no campo do Direito brasileiro ao advogar que o foco da penalidade deveria ser o criminoso e não o crime. Essa idéia serviria para a constituição de um discurso sobre a desigualdade e de uma nova escola penal.

O livro de Marcos César Alvarez pode parecer, à primeira vista, uma história do discurso penal, mas vai muito além da excelente reconstituição histórica de um saber pouco explorado. O estudo parte de uma análise sobre a Criminologia para desenvolver uma reflexão a respeito do nascente pensamento social brasileiro e, principalmente, de um discurso com raízes profundas em nosso país.

Alvarez mostra como a sociedade da Primeira República (1889-1930) lidou com a questão social herdada do Império: o fato problemático de que nos tornamos uma nação independente e, por fim, uma república formada por uma massa analfabeta e miserável. Se no Império vigorava uma forma de lidar com a população baseada na pura e simples brutalidade, o que a instituição da escravidão corroborava, na República, e sob o regime do trabalho assalariado, as elites intelectuais depararam-se com um paradoxo maior: como incorporar ao novo regime político essa massa de desvalidos?

Os juristas reformadores, seguindo nossa tradição autoritária, não tentaram estender a cidadania a todos, mas, antes, procuraram encontrar uma forma de incorporação subordinada do povo brasileiro. Esse objetivo teria como pedra de toque a questão que hoje denominamos de diferença social, que se desdobra em diferença de gênero e idade - mas, no caso brasileiro, sobretudo como diferença étnica e, nos termos da época, racial.

O discurso da Criminologia em ascensão desde a publicação de L'uomo criminoso (1876) de Cesare Lombroso e de obras com apelo similar de Ferri e Garofalo permitia a nossos bacharéis, criminologistas e juristas defenderem uma nova ordem social em que as diferenças eram utilizadas para hierarquizar e, na célebre afirmação de um dos representantes da nova escola penal, tratar desigualmente os desiguais.

Ao contrário da escola clássica do Direito, baseada na igualdade e que tinha como foco o crime, a Criminologia que caracterizava a nova escola penal tinha como objeto o criminoso. Dessa forma, o indivíduo passou a ser qualificado, medido, avaliado de modo a encaixar-se em uma hierarquia. Esse discurso da desigualdade no campo jurídico teve seu momento mais alto quando da teorização de Enrico Ferri sobre o "criminoso nato". Afirmava-se que alguns indivíduos seriam representantes de espécies "bárbaras", "não-civilizadas", que ameaçariam a sociedade civilizada com tendências a cometer atos anti-sociais. Não tardou para que teorias sobre o caráter anormal do criminoso se unissem às teorias raciais para qualificar esses seres "degenerados" como "racialmente inferiores"1.

A Criminologia defendia a necessidade de tornar científico o Direito. No limite, os magistrados deveriam deixar de julgar crimes e aprenderem a julgar a "natureza" dos réus, sua normalidade ou anormalidade biopsíquica. Progressivamente, o apelo a teorias biológicas cedeu espaço a justificativas psicológicas, mas ambas fizeram

\footnotetext{
1 Mike Hawkins (1998) analisa os discursos que naturalizaram desigualdades sociais.
} 
da Criminologia o espaço de convergência entre o saber jurídico e o médico. Essa convergência revela a reorganização da sociedade brasileira nos termos de uma sociedade burguesa e centrada no trabalho livre, portanto na normalização e no disciplinamento dos indivíduos ${ }^{2}$.

As teorias criminológicas respondiam às urgências históricas que se colocavam para certos setores da elite jurídica nacional. A urbanização e industrialização do Brasil republicano deu-se em meio a um grande fluxo migratório europeu. Devido a essas mudanças rápidas e profundas, nossa elite deparou-se com novos temores associados ao crescimento assustador das cidades e, portanto, dos problemas sociais, como más condições de moradia e trabalho, alcoolismo e prostituição.

Se até o fim do Império temiam-se rebeliões escravas, na República emergiram medos diferentes, que tiveram na criminalidade um ponto unificador. Isso já é visível na obra de Viveiros de Castro, A Nova Escola Penal (1894), em que o direito de punir aparece em nova base, a partir do conceito de defesa social e da periculosidade do delinqüente (ALVAREZ, 2003, p. 87) ${ }^{3}$.

A Nova Escola Penal colocou em xeque uma das bases clássicas do direito: o livre arbítrio. Segundo os criminologistas, ele era uma ficção, já que os delinqüentes eram determinados por sua constituição hereditária e, assim, não faziam escolhas livres; antes, eram produto de sua biologia.

Duas categorias receberam especial atenção dos defensores de um direito "científico": mulheres e menores. A Nova Escola defendia não os direitos da mulher, nem mesmo de todas as mulheres. Na verdade, a defesa era apenas a da honra das mulheres honestas ou, traduzindo para nossa linguagem contemporânea, defesa da sociedade androcêntrica e da tutelagem do Estado com relação a esses "seres frágeis".

A defesa social enfatizava a ação preventiva e por isso a questão da menoridade foi seu foco central. A partir disso, o sucesso mais visível da Nova Escola deu-se com a edição do Código de Menores em 1927. Este código incorporou idéias como a do conhecimento e a classificação dos criminosos, a individualização e a indeterminação das penas, além da abolição do júri, que era considerado um anacronismo e, principalmente, a interferência de uma instância não-científica no julgamento. Mais do que uma lei penal, o novo código impunha uma lei social - “mas por lei 'social' deve ser entendido aquilo que os juristas da época entendiam pelo termo: sobretudo uma estratégia ampla de normalização da população pobre” (idem, p. 209).

A busca da cientificidade aproximou o Direito da Medicina Psiquiátrica, fato evidenciado na obra de Nina Rodrigues, que foi o mais importante adepto das teorias de Lombroso no Brasil. A partir delas, defendeu a redução da idade penal, pois considerava que a maioria dos criminosos era formada por mestiços, os quais a "ciência" provara como sendo naturalmente precoces. Dessa forma, Nina Rodrigues levou ao extremo a Antropologia Criminal ao advogar a hierarquização da cidadania baseada em um suposto grau de evolução biológica das "raças".

Os defensores da Nova Escola pleiteavam a reforma do Código Penal, uma reforma penitenciária e outras medidas reformistas com relação à sociedade brasileira como um todo. Assim, seu caráter era ao mesmo tempo reformista e autoritário, marcado por um liberalismo bem brasileiro, ou seja, destituído de qualquer compromisso democrático e de universalização da cidadania. Como observou sabiamente Mariza Corrêa, no Brasil a lei sempre se definiu mais como espaço em que são expressas desigualdades sociais do que como espaço de afirmação da cidadania (idem, p. 246).

A Nova Escola alcançou apenas em parte seus objetivos, mas sem dúvida legou-nos mais do que o Código de Menores, penitenciárias separadas para as mulheres e instituições correcionais para os adolescentes. Ela nos legou um discurso sobre as diferenças sociais que explica e justifica as desigualdades em nosso país. Alvarez apresenta de maneira contundente a emergência do discurso que permite que se trate desigualmente os menos favorecidos e aqueles que não se enquadram no padrão de normalidade da sociedade brasileira ${ }^{4}$.

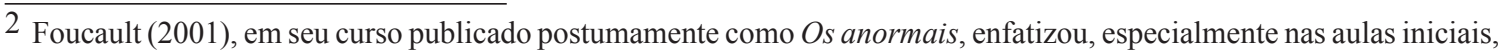
as mudanças no Código Penal francês no século XIX e a crescente influência do experto médico-legal.

3 Michel Foucault abordou esse discurso da defesa social em seu curso no Collège de France publicado há poucos anos no Brasil (FOUCAULT, 2000).

4 Ver, a respeito da oposição normalidade-desvio, Miskolci (2003).
} 
O livro de Alvarez interessará àqueles que lidam de maneira crítica com o nascente pensamento social brasileiro sem temer encarar as complexas relações de nossos intelectuais com matrizes teóricas hoje quase esquecidas, mas das quais somos herdeiros. Alvarez consegue não apenas criar um retrato histórico ou reconstituir uma tradição; antes, ajuda a criticá-la em bases sólidas. Nesse sentido, deve-se mencionar a influência de Michel Foucault, cujas reflexões sobre a constituição da sociedade disciplinar marcam a argumentação. É devido a essa leitura do pensador francês que o autor consegue unir o trabalho de reconstituição histórica do discurso jurídico com a análise sociológica de suas conseqüências na sociedade brasileira.

Ao lidar com a Primeira República, Alvarez avança no tempo e aprofunda algumas das reflexões sobre a elite jurídica do Segundo Império contidas em Os aprendizes do poder (1988) de Sérgio Adorno (aliás, o orientador de Alvarez nesta pesquisa originalmente apresentada como tese de doutorado em Sociologia na Universidade de São Paulo).

Bacharéis, criminologistas e juristas. Saber jurídico e Nova Escola Penal no Brasil expõe de maneira clara e contundente como a elite jurídica da Primeira República buscou formas de tutela e proteção que restringissem o acesso à cidadania aos mais pobres, às mulheres, aos jovens e outros "desviantes". Constatação desoladora sobre o passado, mas que nos permite compreender melhor nosso presente. Alvarez faz-nos refletir sobre o rompimento incompleto com esta tradição reformista e tutelar que ainda relega a maior parte da população brasileira à subordinação e à dependência.

Richard Miskolci (richardmiskolci@uol.com.br) é Doutor em Sociologia pela Universidade de São Paulo (USP) e Professor Adjunto do Departamento de Ciências Sociais da Universidade Federal de São Carlos (UFSCar).

\section{REFERÊNCIAS BIBLIOGRÁFICAS}

ALVAREZ, M. C. 2003. Bacharéis, criminologistas e juristas. Saber jurídico e Nova Escola Penal no Brasil. São Paulo : Método.

FOUCAULT, M. 2000. Em defesa da sociedade. São Paulo : M. Fontes. .2001. Os anormais. São Paulo : M. Fontes.

HAWKINS, M. 1998. Social Darwinism in European and American Thought 1860-1945. Cambridge : Cambridge University.

MISKOLCI, R. 2003. Reflexões sobre normalidade e desvio social. Estudos de Sociologia, Araraquara, n. 1314, p. 109-126. 